\title{
Generation of unstructured meshes using Delaunay triangles for tidal analysis of the port of Acapulco, Mexico
}

\section{Generación de mallas no estructuradas utilizando triángulos Delaunay para el análisis de marea del puerto de Acapulco, México}

AGUILERA-MENDEZ, José María†*, JUAREZ-TOLEDO, Carlos, MARTINEZ-CARRILLO, Irma and VERA-POPOCA, Roberto Ismael

Unidad Académica Profesional Tianguistenco, Universidad Autónoma del Estado de México.

ID $1^{\text {st }}$ Author: José María, Aguilera-Méndez / ORC ID: 0000-0002-9826-421X, CVU CONACYT ID: 66670

ID $1^{\text {st }}$ Coauthor: Carlos, Juárez-Toledo / ORC ID: 0000-0002-7440-3246, Researcher ID Thomson: C-1368-2016, CVU CONACYT ID: 39912

ID $2^{\text {nd }}$ Coauthor: Irma, Martínez-Carrillo / ORC ID: 0000-0002-7952-4418, Researcher ID Thomson: B-9264-2016, CVU CONACYT ID: 39914

ID $3^{\text {rd }}$ Coauthor: Roberto Ismael, Vera-Popoca / ORC ID: 0000-0003-2574-122X, CVU CONACYT ID: 1041051

\begin{abstract}
The main objective of the research is to suggest the use of unstructured meshes in the SWAN wave model because structured meshes require more adjustments in geographically small areas such as rivers, beaches or even bays. Third-party tools and data such as bathymetry, Meteorological Research Forecast (WRF), WaveWatch III (WWIII) and Simulating Waves Nearshore (SWAN) models were used to carry out the research. The aforementioned software and its own developments were used in Acapulco Bay, Guerrero, Mexico for the elaboration of maps that would serve as input in the generation of Delaunay diagrams, which in turn were fundamental parts in the configuration of the experiments and, with this, perform the analysis on the images of the simulations. With the results obtained, it is expected to confirm the validity of the wave data for the bay; therefore, it is considered a useful tool in the process of analysing the natural phenomena present in the port.
\end{abstract}

Delaunay triangles, Unstructured mesh, SWAN Model

\begin{abstract}
Resumen
El objetivo principal de la investigación es sugerir el uso de mallas no estructuradas en el modelo de olas SWAN debido a que las mallas estructuradas requieren más ajustes en áreas geográficamente pequeñas como ríos, playas o incluso bahías. Para llevar a cabo la investigación se utilizaron herramientas y datos de terceros, como batimetría, Meteorological Research Forecast (WRF), WaveWatch III (WWIII) y Simulating Waves Nearshore (SWAN). El citado software y desarrollos propios fueron utilizados en la Bahía de Acapulco, Guerrero, México para la elaboración de mapas que servirían de insumo en la generación de diagramas de Delaunay, los cuales a su vez fueron partes fundamentales en la configuración de los experimentos y, con ello, realizar el análisis sobre las imágenes de las simulaciones. Con los resultados obtenidos, se espera confirmar la validez de los datos de oleaje de la bahía; por tanto, se considera una herramienta útil en el proceso de análisis de los fenómenos naturales presentes en el puerto.
\end{abstract}

Triángulos Delaunay, Mallas no estructuradas, Modelo SWAN

Citation: AGUILERA-MENDEZ, José María, JUAREZ-TOLEDO, Carlos, MARTINEZ-CARRILLO, Irma and VERAPOPOCA, Roberto Ismael. Generation of unstructured meshes using Delaunay triangles for tidal analysis of the port of Acapulco, Mexico. Journal Simulation and Laboratory. 2021, 8-24: 20-27

\footnotetext{
*Correspondence to Author (email: jaguileram001@alumno.uaemex.mx)
}

$\dagger$ Researcher contributing as first Author. 


\section{Introduction}

The terrestrial models implementation has started from the latitude-longitude type equidistant meshes generation that give meaning to the way in which our planet is modelled. These representations have a problem that until now has been worked on to solve: it is the distance at the poles and the equator, as well as its representation both numerically and geometrically. It is in the 90's that regular triangular-type icosahedral meshes began to be used, which provide a homogeneous globe coverage. This representation avoids the socalled pole problem related to the meridians convergence in latitude-longitude meshes while providing good computational efficiency (García, 2009; Legrand et al., 2000; Ruppert, 1995; Zijlema, 2010). The first representations were through the Voronoi diagrams, which in turn allow the introduction of the Delaunay triangles; creating the unstructured grid concept.

Unstructured grids are very used to simulations study area, initially unstructured grid concept, this concept was applied only in the context of the areas near of the poles or small fast changing areas, but it has been shown that its use transcends much larger areas and that its use in extreme situations such as hurricanes has begun to spread (Dietrich et al., 2012; García, 2009; Huang et al., 2013). Figure 1 shows the Acapulco Bay bathymetry, the scale at right indicates the seabed deep in meters and shows a great variation in depth in areas closer to the coast; That is why their analysis is of interest due to the changes in the tide that occur there, which generate a characteristic bays effect with a closed neck and shallow depth.

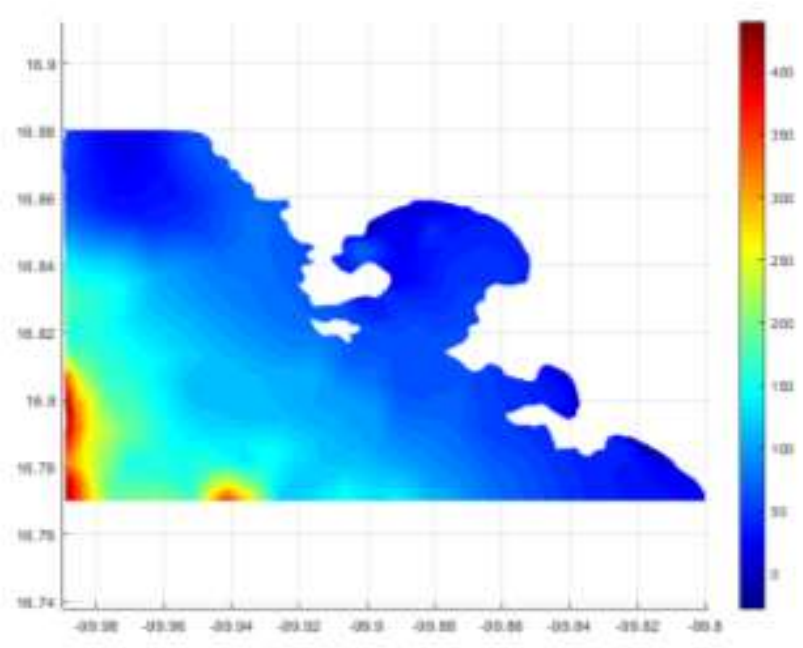

Figure 1 Acapulco Bay bathymetry

Source: Own Elaboration
This work explains about the unstructured grid elaboration of Acapulco bay, Mexico, as a basis for waves simulation to obtain the frequency (Tm01) and height (Hsig) variables values that describe the presence of long and continuous swell generated by storms at sea (deep sea phenomenon) on the bay beaches.

The representation through Delaunay triangles was used as the unstructured grid, the Conforming Delaunay Triangulation (CDT) is obtained from working with Restricted Delaunay Triangulations (RDT) to which a series of additional artificial vertices called Steiner points are added, which help them comply with the laws of Delaunay triangulation (Shewchuk, 2002). Obtaining a conformal triangulation facilitates the generation of a consistent mesh that suggests that all the mesh vertices belong to a triangle and that this triangle fulfil the area, internal angles and circumferences criteria, among others, improving the result quality (Ruppert, 1995). Whichever method is used to generate the Steiner points; it is useful to smooth the mesh using a Laplacian filter. Then each point is smoothed $\mathrm{N}$ times according to

$X_{0}^{n+1}=X_{0}^{n}+\omega \sum_{i=1}^{M} \frac{X_{0}-X_{i}}{M}$

where $X_{0}^{n+1}$ is the new position of the point $X_{0}^{n}, \mathrm{M}$ is the number of neighboring points with coordinates $X_{i}$ and $\omega$ the relaxation parameter. The number of iterations should be within the range 20 to 50 and the standard relaxation parameter is within 0.05 to 0.25 .

The way to determine the generation unstructured grids method will depend on the system selected for the simulation runs. One of the ways that exist to represent bodies in 2-D is the Planar Straight Line Graph (PSLG) format, which is defined as a collection of vertices and segments, where the end points of each segment are included in the vertices list, and it has the possibility to specify the constraints on angles, triangle areas, holes and concavities (Chen \& Bishop, 1997).

This paper uses a series of experiments with different triangles area manipulation to establishing a maximum area. 
The minimum angle and the Steiner points, provide a definition of the unstructured grid that is precise enough to solve many types of problems about materials, fluids, surfaces, etc. (Dietrich et al., 2012; Legrand et al., 2000; Weatherill, 1992; Zijlema, 2009). To avoid malformed grids and errors at model's runtime, a conventional restriction that must be met is that the angles within each triangle must be less than the value defined below: let $\mathrm{a} \rightarrow$ and $\mathrm{b} \rightarrow$ be the tangential vectors of two faces of a triangle, then the $\cos \varnothing<-0.8$ or, equivalently, $\varnothing>143^{\circ}$.

$\cos \varnothing=\frac{\vec{a} \cdot \vec{b}}{|\vec{a}||\vec{b}|}$

The equation 2 has been used as part of the software simulation requirement and the area bathymetry will be used to work on the location and placement of a higher resolution in the shallower area to study the wave frequency and height variables on the beaches or, in our case, better monitoring of the swell phenomenon in its generation, dispersion and scope stages.

Studies that refer to the behaviour of fluids and, specifically to the SWAN software model, accept that the variation of the measurements has ranges of up to $\pm 30 \%$ depending on the computer processor and operative system, as well as the configuration of the physics and the grid used in the simulation (Booij et al., 1999; Reikard \& Rogers, 2011; Zijlema, 2010). This study will consider acceptable a $\pm 10 \%$ variation in the variable values when comparing one type of structured grid against the other two unstructured grids to establish the simulation validity since the only element that will vary between experiments are the triangle angles and area in unstructured grids.

An additional reason to seek the models execution with an unstructured grid was to avoid the results that show biases such as the so-called "sawtooth" that directly affect the models output representation and interpretation as shown in the figure 2 .

One of the principal causes of biased maps is the information quantity and quality that exists about the area; when the information lack is in the input phase, it is tending to solve it through the use of interpolations in addition to the use of higher resolution grids. In our case, the area is so small that we lack detailed information about the tide and the wind; therefore, the interpolation of both variables was used.
In the output phase, is an input consequence, configuration mistake or outdated maps.

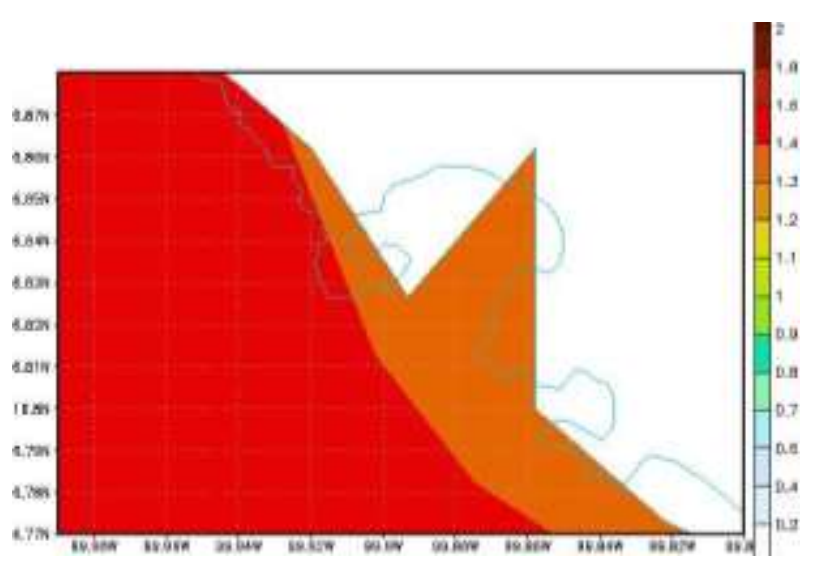

Figure 2 Image showing "sawtooth" bias as a result of structured grid analysis with metadata Source: Own Elaboration

\section{Development}

The Acapulco bay area is located between coordinates $16.77^{\circ}$ to $16.88^{\circ}$ north latitude and $99.80^{\circ}$ to $99.99^{\circ}$ west longitude; with an approximate area of $245 \mathrm{~km}^{2}$. The area bathymetry has a grid resolution defined with an interval of 15 arc seconds, or one point approximately every $0.004^{\circ} \quad$ (GEBCO Compilation Group, 2020). Therefore, due to its size, location, bathymetry and geographical features, the Acapulco Bay represents an excellent opportunity to study the tidal phenomenon through wave modelling software on shore.

The area geography was obtained from a map that served as a template that, once visualized in digital form, proceeded to the unstructured grid point's location for both the coastal areas and the work area limits. As mentioned, special interest was placed in beach areas and areas with shallower depth so that the height and frequency waves variables evaluation would show their variations in short distances and obtain a better perspective of their behaviour; for the area margins to be studied, the vertices with a greater separation were considered because the margins conditions do not significantly affect the experiment development. With the obtained points, the PSLG file was created with 243 vertices, 243 segments, 3 interior boundary edges and 1 hole. The identified points are shown in the Figure 3.

AGUILERA-MENDEZ, José María, JUAREZ-TOLEDO, Carlos, MARTINEZ-CARRILLO, Irma and VERA-POPOCA, Roberto Ismael. Generation of unstructured meshes using Delaunay triangles for tidal analysis of the port of Acapulco, Mexico. Journal Simulation and Laboratory. 2021 
Once the continuity of the structure was assured, it was necessary to identify holes or, in our case, the Roqueta Island as an object outside the calculation and the different figure segments, the unstructured grid was generated with the Delaunay triangles using the divide and conquer method. Early attempts to generate the unstructured grid from the PSLG file, yielded an RDT that is similar to a Delaunay triangulation, but each PSLG segment is present as a single edge in the triangulation. An RDT is not really a Delaunay triangulation (Romero \& Barrón Fernández, 2016; Shewchuk, 2002), some of the triangles may not be Delaunay, but all are RDT. The result yielded 241 vertices, 241 triangles and 482 grid edges (see figure 4).

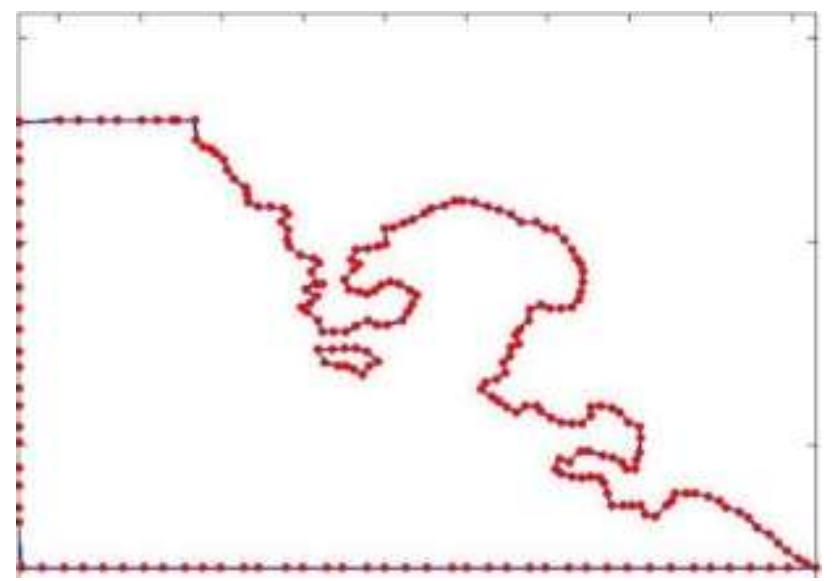

Figure 3 Origin points location for the unstructured grid generation

Source: Own Elaboration

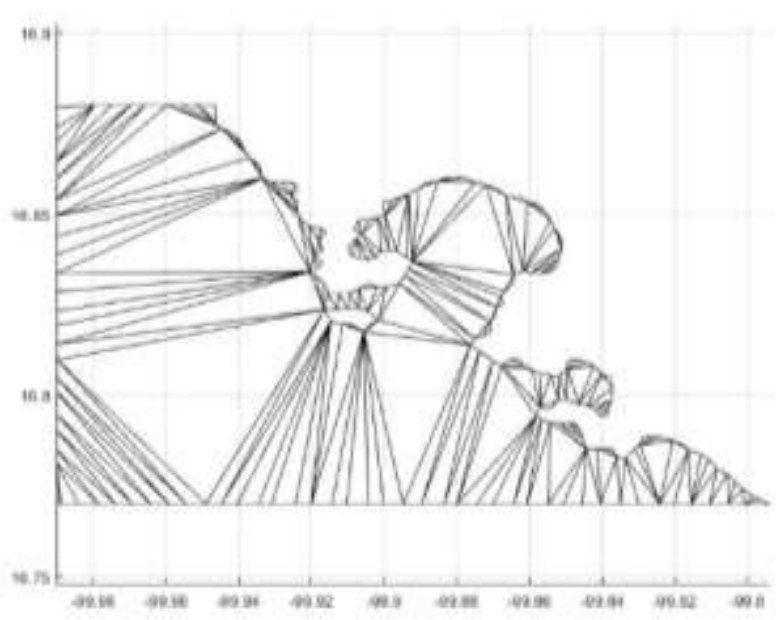

Figure 4 Diagram generated from RDTs Source: Own Elaboration

One simple way to increase employee efficiency of figure 3 is to add a minimum angle value that, together with the Steiner points, would generate a CDT grid from the PSGL. Then 20o was established as the minimum angle value.
When executing the triangulation program, 346 vertices, 443 triangles, 789 grid edges were obtained, which improved the quality of the result as shown in Figure 5. In the unstructured grid design final stage, a minimum angle of $30^{\circ}$ was established with a maximum area of $100 \mathrm{~m}^{2}$ per triangle.

The result obtained was 496 vertices, 730 triangles and 1226 grid edges. In all cases, the main objectives were the Delaunay triangulation preservation and the grid quality assurance. The result is shown in Figure 6. As can be seen, the size of the triangles tends to be smaller in the areas close to the beach where the depth is lower, which results in greater currents dynamics and therefore in the study variables.

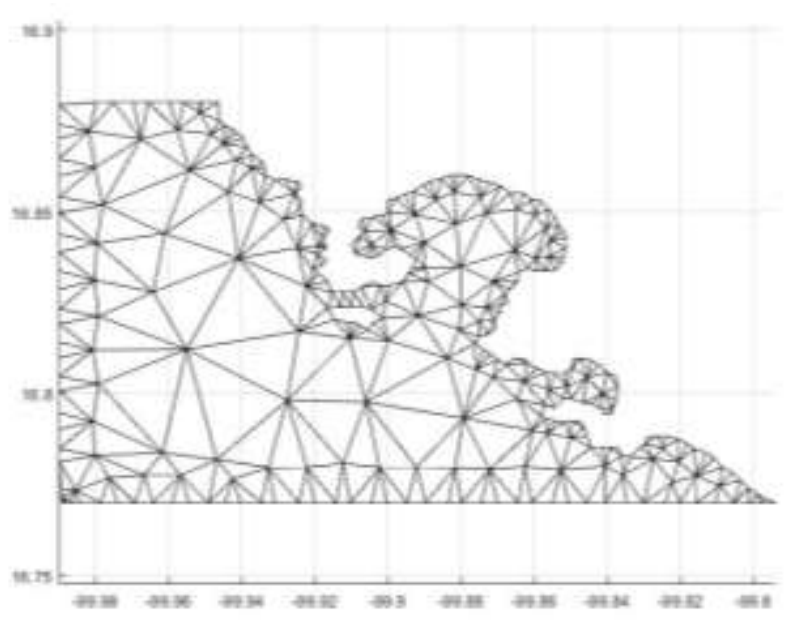

Figure 5 Diagram generated from CDTs Source: Own Elaboration

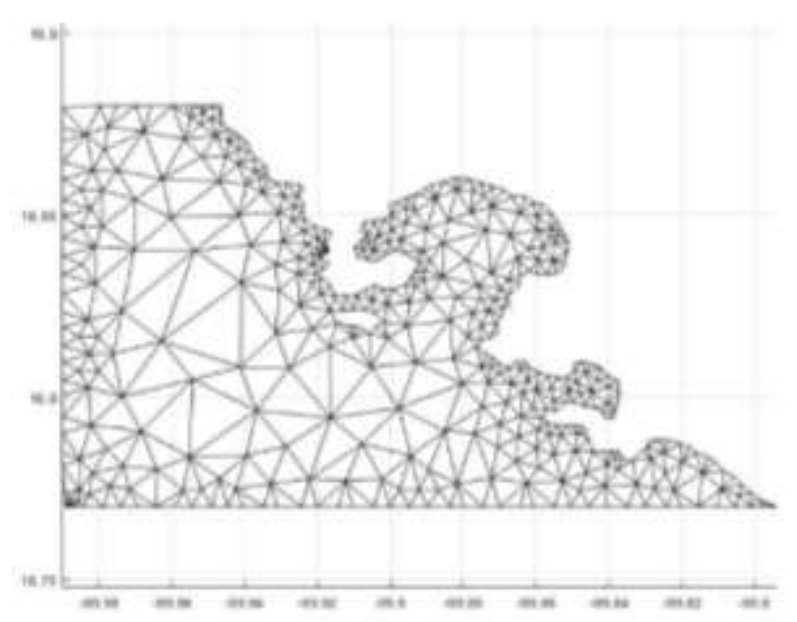

Figure 6 Diagram generated with the limitation of area and angles greater than $30^{\circ}$ Source: Own Elaboration 
When observing the previous figure definition, its refinement was sought to provide information that did not leave the option of error (by decimal rounding) to the simulation when calculating the triangles angles, therefore, the unstructured grid was staked with a minimum angle of $33^{\circ}$ with a maximum area of $100 \mathrm{~m}^{2}$ per triangle, the result obtained was 679 vertices, 1087 triangles and 1776 grid edges. As can be seen in the Figure 7, the trend is that the size of the triangles becomes smaller in beach areas.

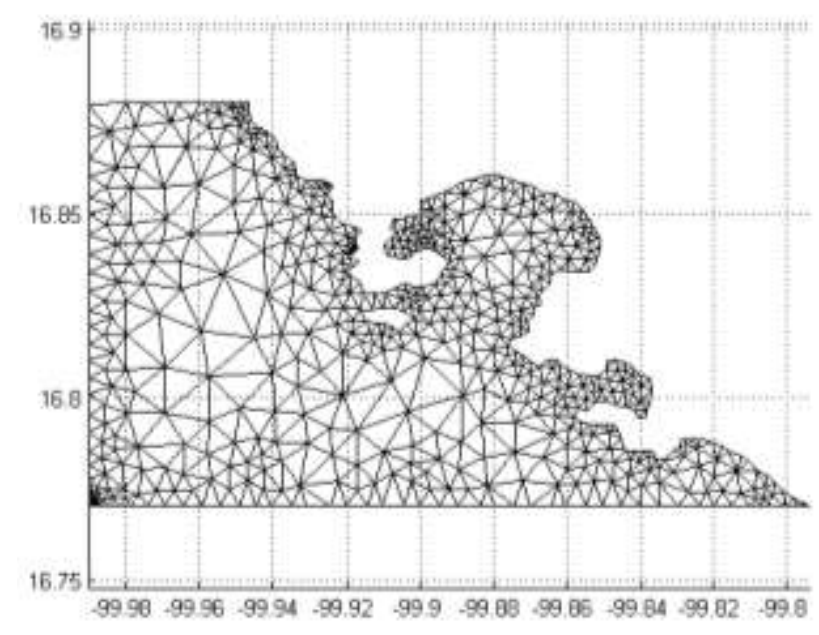

Figure 7 Diagram generated with the limitation of area and angles greater than $33^{\circ}$

Source: Own Elaboration

Subsequently, the wind information (direction and speed) were extracted from the WRF model, as well as the tidal information (frequency, height and direction) from the WWIII model in order to run the corresponding simulations in the SWAN software. The wave simulation algorithm can use both structured and unstructured grids so the experiment should not present considerable variations that could be due to the style, the way of programming the code or the design architects; in both solutions, a bathymetry of 1,196 points was taken, covering both the marine and terrestrial area within the study coordinates.

For wind and tidal data, the data were fed only for latitude $16.75^{\circ}$ and longitude $-100.0^{\circ}$; due to the area size and their availability due to the models resolution. Each execution was carried out at 00, 03, 06, 09, 12, 15, 18 and 21 hours for each day, for a cycle of 3 months of temporary. The marine physics variables were considered with the default model values, as well as the GEN3 calculations offered by SWAN; finally, the JONSWAP quotient was used for friction.

\section{Results}

The following points are used to determine the efficiency of the method: $\mathrm{pl}\left(-99.90^{\circ}, 16.84^{\circ}\right)$, $\mathrm{p} 2\left(-99.89^{\circ} .16 .85^{\circ}\right), \quad \mathrm{p} 3\left(-99.88^{\circ}, 16.85^{\circ}\right), \quad \mathrm{p} 4(-$ $\left.99.86^{\circ}, 16.84^{\circ}\right)$ and $\mathrm{p} 5\left(-99.88^{\circ}, 16.83^{\circ}\right)$. The model to be executed with the structured grid was compiled with the gcc and gfortran compilers, in addition the use MPICH library. The simulation results for 08/07/2021 12: $00 \mathrm{Z00}$ are shown in tables 1,2 and 3 .

\begin{tabular}{|l|r|r|r|r|}
\hline \multicolumn{6}{|c|}{ Run:0.10 Table: valida_estruct, SWAN version:41.31A } \\
\hline Point & Xp $($ deg $)$ & Yp (deg) & Hsig $(\mathrm{m})$ & Tm01 (s) \\
\hline p1 & 99.900 & 16.8400 & 1.22435 & 12.2464 \\
\hline p2 & 99.890 & 16.8500 & 1.69673 & 12.9411 \\
\hline p3 & 99.880 & 16.8500 & 1.59793 & 12.2941 \\
\hline p4 & 99.860 & 16.8400 & 1.32819 & 12.5719 \\
\hline p5 & 99.880 & 16.8300 & 1.31129 & 11.2290 \\
\hline
\end{tabular}

Table 1 Simulation results using a structured grid Source: Own Elaboration

\begin{tabular}{|l|r|r|r|r|}
\hline \multicolumn{5}{|c|}{ Run:0.20 Table:valida30, SWAN version:41.31A } \\
\hline Point & Xp $($ deg $)$ & Yp $($ deg $)$ & Hsig $(m)$ & Tm01 (s) \\
\hline p1 & 99.900 & 16.8400 & 1.30604 & 12.8037 \\
\hline p2 & 99.890 & 16.8500 & 1.65372 & 13.1451 \\
\hline p3 & 99.880 & 16.8500 & 1.45979 & 12.7073 \\
\hline p4 & 99.860 & 16.8400 & 1.37198 & 12.5821 \\
\hline p5 & 99.880 & 16.8300 & 1.34549 & 11.5210 \\
\hline
\end{tabular}

Table 2 Simulation results using an unstructured grid with triangle angles greater than $30^{\circ}$

Source: Own Elaboration

\begin{tabular}{|l|r|r|r|r|}
\hline \multicolumn{5}{|c|}{ Run:0.30 Table:valida33, SWAN version:41.31A } \\
\hline Point & Xp (deg) & Yp (deg) & Hsig (m) & Tm01 (s) \\
\hline p1 & 99.900 & 16.8400 & 1.47334 & 12.0187 \\
\hline p2 & 99.890 & 16.8500 & 1.58858 & 13.1557 \\
\hline p3 & 99.880 & 16.8500 & 1.48878 & 12.7870 \\
\hline p4 & 99.860 & 16.8400 & 1.39658 & 12.6446 \\
\hline p5 & 99.880 & 16.8300 & 1.38802 & 11.6278 \\
\hline
\end{tabular}

Table 3 Simulation results using an unstructured grid with triangle angles greater than $33^{\circ}$

Source: Own Elaboration

The results are consistent and do not exceed the $\pm 10 \%$ variation that was proposed from the beginning as a reference value to accept. The model was configured to generate files with a greater amount of information, (see figures 8 and 9). 


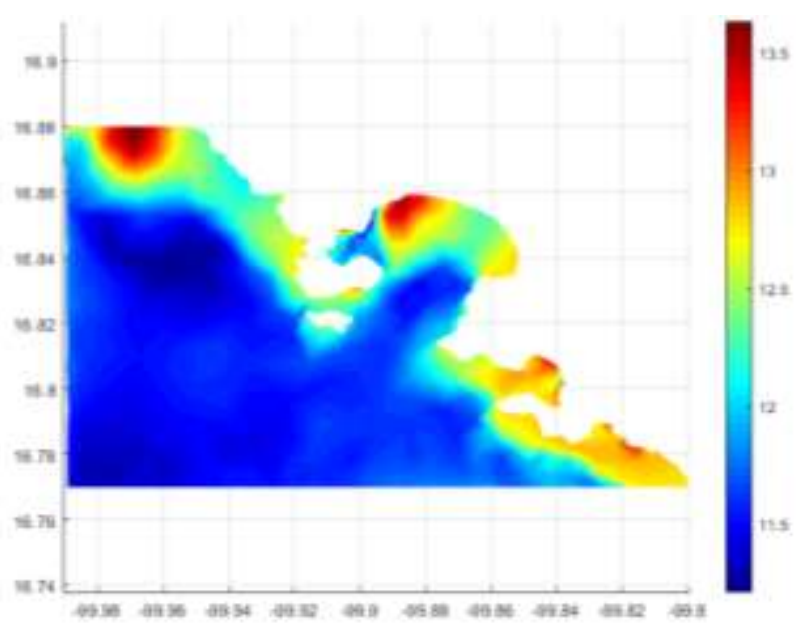

Figure $8 \mathrm{Tm} 01$ with triangle angle greater than $30^{\circ}$ Source: Own Elaboration

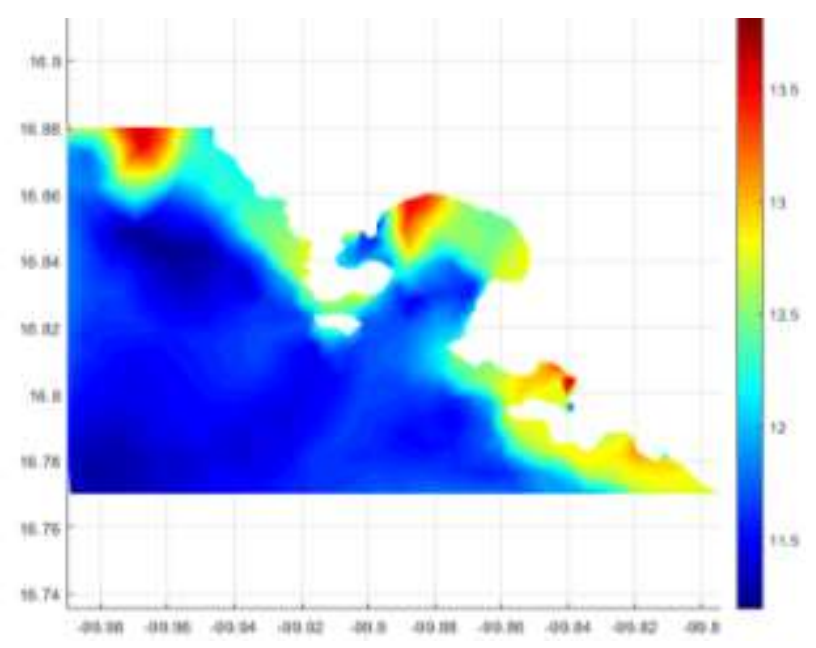

Figure $9 \mathrm{Tm} 01$ with triangle angle greater than $33^{\circ}$ Source: Own Elaboration

The three models evaluated yielded values that were very similar to each other. The ease of model manipulation and the time-equipment necessary for simulations with unstructured grids is a factor that has favoured its use and, therefore, its adaptation in different scenarios. On the other hand, we do not have marine equipment or buoys sensitive enough to determine if the $30^{\circ}$ or $33^{\circ}$ diagram was more accurate;

What is reflected is that in an unstructured grid it is recommended to use triangles with angles not less than $30^{\circ}$ that allow establishing in the interest areas or high impact a network that is capable of transmitting the smallest variations in a timely and reliable manner in the as little time as possible, according to the data with which it is fed and it is at the alert moment when the information precision becomes relevant; especially if you are talking about a deep draft port and a tourist area.
When observing the data obtained in the control points, it can be said that the results are consistently similar; not so the general representation of the study area where, although when observing the scales, the differences are minimal, the areas of coverage of the phenomena would not be. Which is perfectly justified due to the variation that exists in the meshes and their angles; Therefore, it is concluded that the measurement of the phenomenon and the area of impact have variations that do not affect or generate a significant error within the predictions. For the case of $30^{\circ}$ and $33^{\circ}$ angles, from the data generated by the simulations, the frequency variable was processed.

For the wave height variable, the figures 10 and 11 were generated with the unstructured data, both for 30o and 33o, again we observe that the figure complicates the analysis objectivity so it could be discarded despite the values similarity.

The results obtained from the simulations were finally compared against the data recorded from the meteorological and oceanographic stations that the bay had. The comparison of the data gave us a variation of less than $\pm 10 \%$ with respect to the measurements of the structured grid against the unstructured grid for both cases of angles.

As an additional measure, the information was corroborated through press bulletins and phenomenon visual confirmation. In terms of CPU usage and execution time, the unstructured grid had a better performance running on a single processor in 01 minutes 29 seconds average time.

The calculation on the structured grid took 02 minutes and 50 seconds, on average, with 10 cores in parallel processing. The executions analysis indicated that in the unstructured grids the sufficiency conditions established in the model were reached with a lower number of iterations, not so in the structured grid that generally reached the top of 50 iterations. 


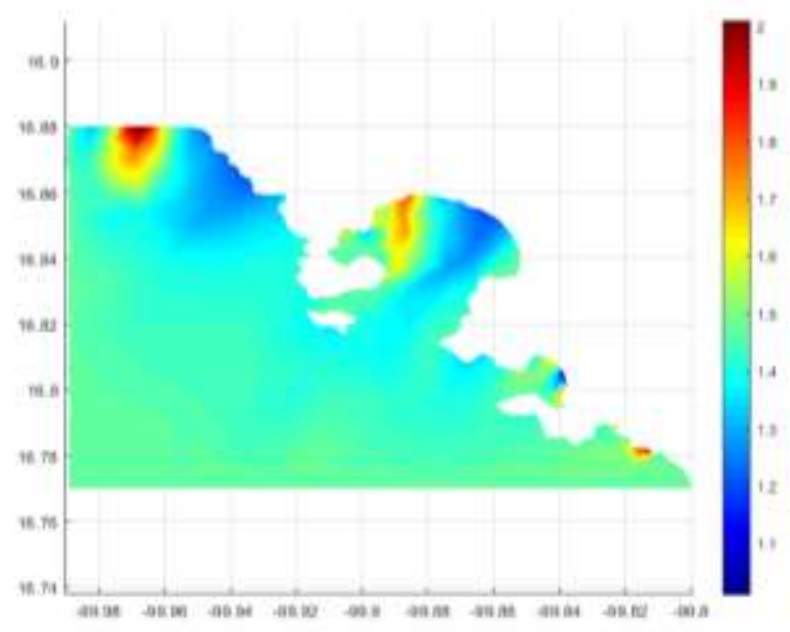

Figure $10 \mathrm{Hsig}$ with triangle angle greater than $30^{\circ}$ Source: Own Elaboration

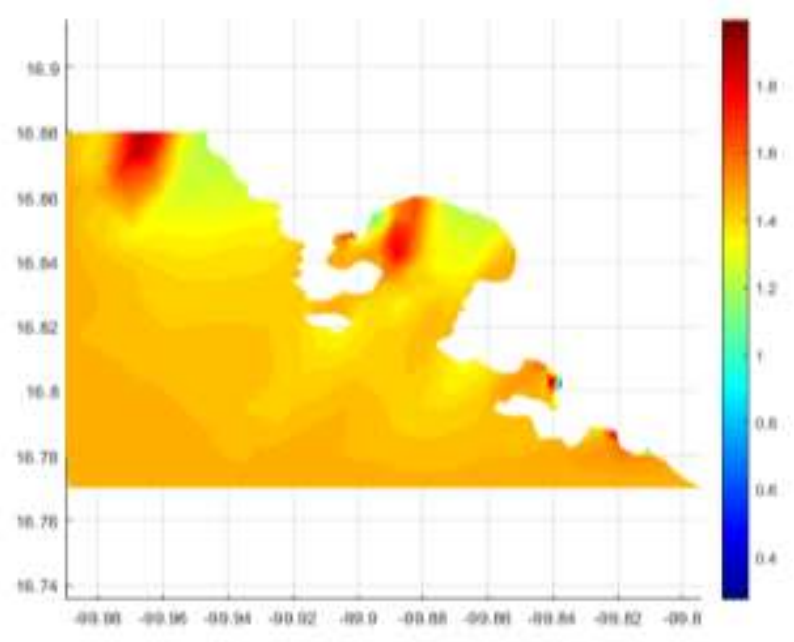

Figure $11 \mathrm{Hsig}$ with triangle angle greater than $33^{\circ}$ Source: Own Elaboration

\section{Conclusions}

In this study, the results of two different executions on the same area have been shown, the usual structured grid of figure 2 and the unstructured grid models (figures 6 and 7). The images generated for the structured grid presented the sawtooth bias. The results presented in tables 1,2 and 3 form were very similar and did not exceed the threshold of $\pm 10 \%$; even the control points indicated in the simulations yielded information that helped the best comparison of the experiments, so their observation and analysis was of great help in making decisions.

In this series of experiments at least $30^{\circ}$ angles were used; and the use of larger angles is expected in future approximations to find the best ways to represent marine phenomena and their effects on beaches.
In addition to this variable, there are different model physics variables that must be considered to make broader projections about the behaviour of the sea under certain conditions and at different points on earth. Friction, density of water, level of salinity, pollution, etc. these are just some of the variables that should be discussed for future experiments.

\section{Acknowledgments}

Secretaría de Investigación y Estudios Avanzados de la Universidad Autónoma del Estado de México.

Consejo Nacional de Ciencia y Tecnología (CONACYT), México.

\section{References}

Booij, N., Ris, R. C., \& Holthuijsen, L. H. (1999). A third-generation wave model for coastal regions 1. Model description and validation. Journal of Geophysical Research: Oceans, 104(C4), 7649-7666. https://doi.org/10.1029/98JC02622

Chen, H., \& Bishop, J. (1997). Delaunay Triangulation for Curved Surfaces. Proc. of the 6th Int. Meshing Roundtable. http://www.imr.sandia.gov/papers/imr6/chen97. ps.gz

Dietrich, J. C., Tanaka, S., Westerink, J. J., Dawson, C. N., Luettich, R. A., Zijlema, M., Holthuijsen, L. H., Smith, J. M., Westerink, L. G., \& Westerink, H. J. (2012). Performance of the Unstructured-Mesh, SWAN+ADCIRC Model in Computing Hurricane Waves and Surge. Journal of Scientific Computing, 52(2), 468-497. https://doi.org/10.1007/s10915-0119555-6

García, F. (2009). Unestructured Mesh Generation for Numeric Models Implementation. Dyna, 76(157), 17-25.

GEBCO Compilation Group. (2020). GEBCO. https://doi.org/10.5285/a29c5465-b138-234de053-6c86abc040b9 
Huang, Y., Weisberg, R. H., Zheng, L., \& Zijlema, M. (2013). Gulf of Mexico hurricane wave simulations using SWAN: Bulk formulabased drag coefficient sensitivity for Hurricane Ike. Journal of Geophysical Research: Oceans, 118(8), 3916-3938. https://doi.org/10.1002/jgrc.20283

Legrand, S., Legat, V., \& Deleersnijder, E. (2000). Delaunay mesh generation for an unstructured-grid ocean general circulation model. Ocean Modelling, 2(1-2), 17-28. https://doi.org/10.1016/S1463-5003(00)000056

Reikard, G., \& Rogers, W. E. (2011). Forecasting ocean waves: Comparing a physicsbased model with statistical models. Coastal Engineering, 58(5), 409-416. https://doi.org/10.1016/j.coastaleng.2010.12.00 1

Romero, N., \& Barrón Fernández, R. (2016). Delaunay Triangulation Validation Using Conformal Geometric Algebra. Computación y Sistemas, 20(4), 789-798. https://doi.org/10.13053/cys-20-4-2387

Ruppert, J. (1995). A Delaunay Refinement Algorithm for Quality 2-Dimensional Mesh Generation. Journal of Algorithms, 18(3), 548585. https://doi.org/10.1006/jagm.1995.1021

Shewchuk, J. R. (2002). Delaunay refinement algorithms for triangular mesh generation. Computational Geometry, 22(1-3), 21-74. https://doi.org/10.1016/S0925-7721(01)000475

Weatherill, N. P. (1992). Delaunay triangulation in computational fluid dynamics. Computers \& Mathematics with Applications, 24(5-6), 129$150 . \quad$ https://doi.org/10.1016/08981221(92)90045-J

Zijlema, M. (2010). Computation of wind-wave spectra in coastal waters with SWAN on unstructured grids. Coastal Engineering, 57(3), 267-277.

https://doi.org/10.1016/j.coastaleng.2009.10.01 1

$\begin{array}{lrr}\text { Zijlema, M. } & \text { (2009). } & \text { PARALLEL, } \\ \text { UNSTRUCTURED } & & \text { MESH } \\ \text { IMPLEMENTATION } & \text { FOR } & \text { SWAN. Coastal } \\ \text { Engineering } & 2008, & 470-482 . \\ \text { https://doi.org/10.1142/9789814277426_0040 }\end{array}$

.

